\title{
A case of Lenz microphthalmia syndrome
}

F Ferda Özkinay, Cihangir Özkinay, Hasan Yüksel, Ayse Yenigun, Gül Sapmaz, Oguz Aksu

\begin{abstract}
Lenz microphthalmia syndrome was first described by Lenz et al in 1955 . The cardinal features of the syndrome are microphthalmia or anophthalmos, narrow shoulders, other skeletal anomalies, and dental and urogenital malformations.

Here we present a case of Lenz microphthalmia syndrome who shows the typical characteristics and, additionally, dysgenesis of the corpus callosum associated with dilatation of the lateral ventricles.

The patient, a 13 year old male, was referred to our hospital by a dental hospital for genetic counselling. On physical examination, height, weight, and head circumference were below the 3 rd centile and he had brachymicrocephaly, a preauricular tag, microphthalmia, missing teeth, narrow shoulders, long, proximally placed thumbs, hypospadias, cryptorchidism, and a normal IQ. Ophthalmological examination showed microcornea, sclerocornea, absence of the pupil, no vision in the left eye and decreased vision and a small pupil in the right eye in addition to his bilateral microphthalmia. Cranial MRI showed dilatation of the lateral ventricles and dysgenesis of the corpus callosum.
\end{abstract}

(F Med Genet 1997;34:604-606)

Keywords: Lenz microphthalmia syndrome; microphthalmia; corpus callosum dysgenesis

Lenz microphthalmia syndrome, described by Lenz et $a l^{1}$ in 1955 , is a rare genetic disorder. About 20 cases have been published to date. Cardinal features of the syndrome are unilateral or bilateral microphthalmia, ear deformities, microcephaly, dental, skeletal, and urogenital abnormalities, and mental retardation. ${ }^{1-3}$ The syndrome is inherited in an $\mathrm{X}$ linked recessive fashion. Affected males are always infertile. Differential diagnosis includes autosomal recessive anophthalmia and autosomal recessive or X linked microphthalmia.

Here we present a case of Lenz microphthalmia syndrome who also has dysgenesis of the corpus callosum associated with dilatation of the lateral ventricles in addition to the typical features of the syndrome. This is the first reported case of Lenz microphthalmia with these other anomalies.

\section{Case report}

A 15 year old male patient was referred to our hospital by a dental hospital for genetic counselling. He was born at 32 weeks of gesta- tion to non-consanguineous parents after a $\stackrel{\mathbb{D}}{\rightarrow}$ normal vaginal delivery. There were no other family members with similar features. The mother had had eight pregnancies of which four were aborted by her own choice in the first trimester. The patient was one of the products of a twin pregnancy. His twin sib was a healthy female. The other three sibs were normal males.

Developmental delay was detected in childhood: he gained head control at 3 months, sat at 2 years, walked at 3 years, and gained bladder and bowel control at 5 years. He was attending a special school for people with visual deformities and was in the ninth grade. His mental development seemed to be slightly subnormal.

On physical examination at 15 years old, his weight $(31.5 \mathrm{~kg})$, height $(150 \mathrm{~cm})$, and head circumference $(46 \mathrm{~cm})$ were below the $3 \mathrm{rd}$ centile. He had a long head, sparse hair, prominent nasal bridge, bilateral microphthalmia, and abnormal ears that were anteverted, prominent, and had poorly developed and thin antihelices with a preauricular tag on the left side (figs 1 and 2) The teeth were hypoplastic, irregular, and widely spaced. He had a highly arched palate and long philtrum. His neck was long with sloping shoulders. The thumbs were long and proximally placed. He had a sacral dimple, a cigarette paper scar on his back (fig 3), a hydrocele on the right side, and incomplete hypospadias. The urethral orifice was dorsally placed.

Ocular examination showed bilateral microphthalmia, microcornea, absence of the pupil and no vision in the right eye, and a small pupil and diminished vision in the left eye. Radiographs showed hypoplastic clavicles.

Laboratory tests (complete blood count, urine analysis, blood electrolytes, liver and renal function tests) and abdominal ultrasonography were normal.

On cranial magnetic resonance imaging (MRI) a dysgenetic corpus callosum and dilatation of the temporal horns of the lateral ventricles were observed (fig 4). Chromosomes were normal. The clinical features of the patient are shown in table 1 .

\section{Discussion}

Microphthalmia is one of the cardinal features of a number of syndromes. ${ }^{4}$ Among these, oculo-dento-osseous syndrome, cerebrooculo-facio-skeletal syndrome, and Goltz syndrome show the most similar findings to Lenz microphthalmia syndrome. Common features of these syndromes are microphthalmia, dental changes, and skeletal deformities. 


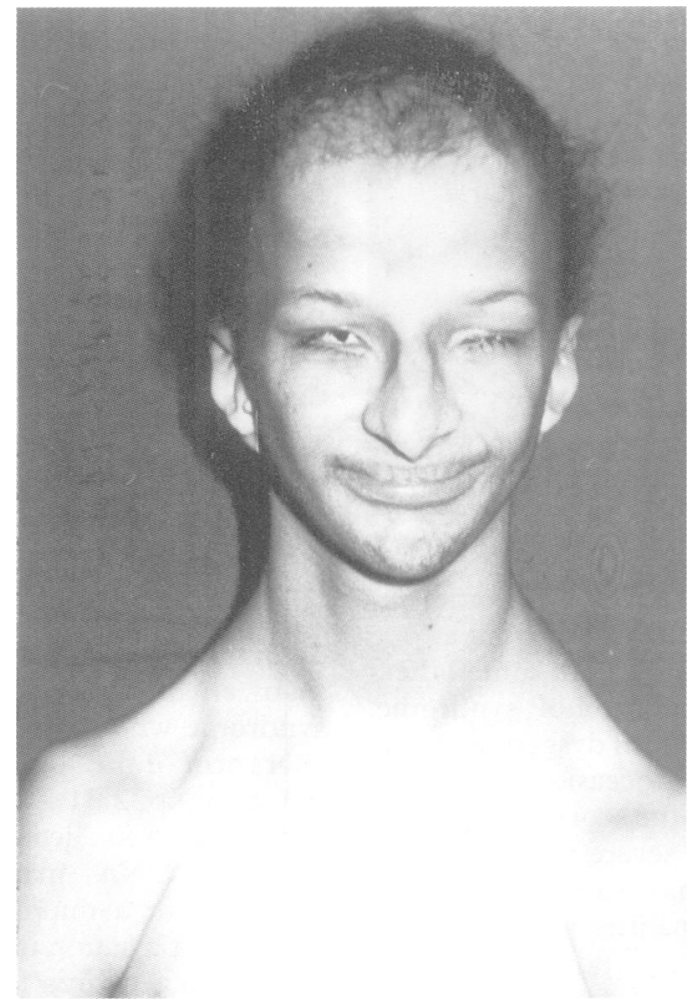

Figure 1 Front view of the patient. Note the high forehead, bilateral microphthalmia, prominent nose, long neck, and sloping shoulders.

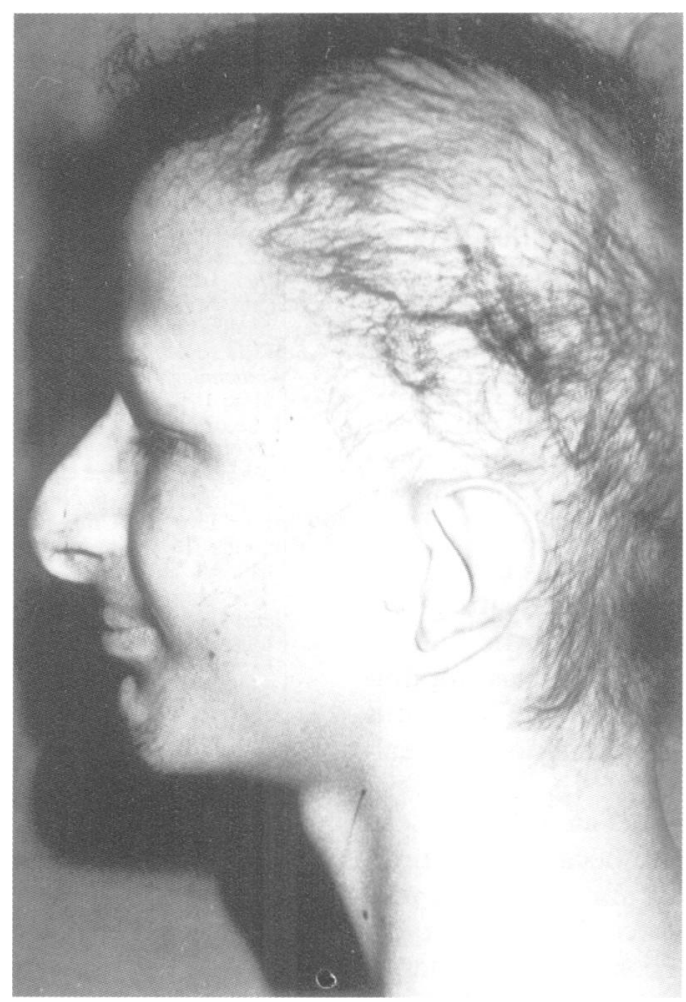

Figure 2 Lateral view of the patient showing sparse hair, prominent nasal bridge, thin and poorly developed antihelix, and preauricular tag.

In cerebro-oculo-facio-skeletal syndrome (COFS), inherited as an autosomal recessive trait, survival is rare after the age of 5 years. ${ }^{4}$ Patients with COFS usually show generalised hypotonia, areflexia, camptodactyly, flexion contractures of the elbows and knees, and osteoporosis, in addition to microphthalmia. ${ }^{5-7}$ Our case does not show the cardinal features of

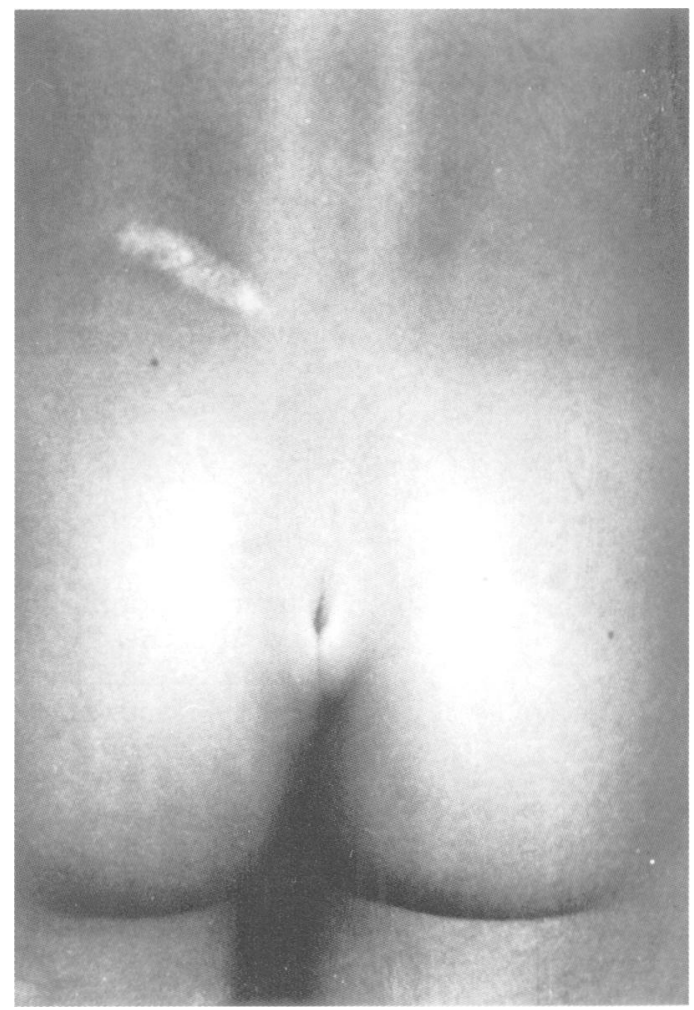

Figure 3 Sacral dimple and scar.

Table 1 Clinical features of the patient

\section{General}

Developmental retardation

Growth retardation

Cranium and brain

Microcephaly

Long head

Sparse hair

Dysgenesis of corpus callosum

Dilated lateral ventricles

Eyes

Microphthalmia

Microcornea

Sclerocornea

Small pupil

Diminished vision

Ears

Prominent and poorly developed

Mouth

Long philtrum

High arched palate

Abnormal teeth

Skeletal abnormalities

Short clavicles

Sloping shoulders

Long and proximally placed thumbs Genital

Hydrocele

Hypospadias

the syndrome described above with the exception of the eye findings.

MRI showed dysgenesis of the corpus callosum in our patient. Morphological abnormalities of the corpus callosum can be divided into three categories: agenesis, hypoplasia, and hypogenesis. In agenesis the corpus callosum is totally absent. In hypogenesis the caudal or corpus part of the corpus callosum is shortened. Hypoplasia refers to a thin corpus callosum that is commonly associated with cortical dysgenesis. ${ }^{8}$ In a number of syndromes morphological abnormalities of the corpus callosum are associated with other abnormalities. Some of these syndromes, such as acrocallosal syndrome, frontonasal dysplasia, Anderman 


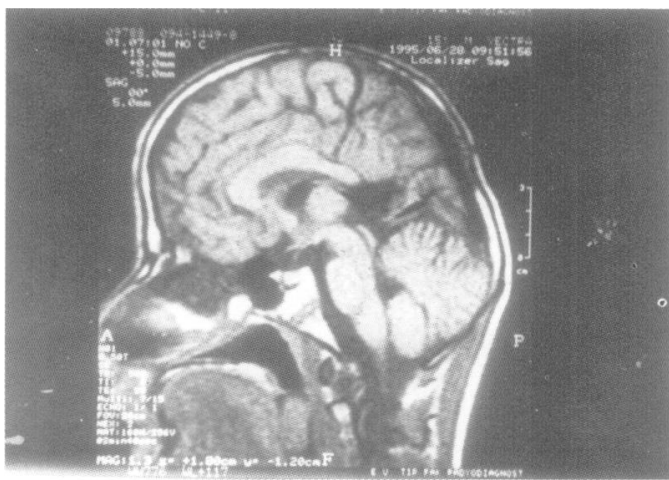

Figure 4 MRI scan of the patient showing dysgenetic corpus callosum.

Shapiro syndrome, and Fryns syndrome, include dysgenesis of the corpus callosum as one of their cardinal features, while in some others (Meckel syndrome, fetal alcohol syndrome, Dandy-Walker malformation) dysgenesis of the corpus callosum is an occasional or rare abnormality. ${ }^{9}$ Whether the corpus callosum abnormalities can cause severe CNS dysfunction is still not clear. It has been reported that corpus callosum abnormalities are commonly found within the healty population. ${ }^{10}$ In another report the authors found that dysgenesis of the corpus callosum is common in people with learning disabilities. ${ }^{11}$

The cases of Lenz microphthalmia syndrome reported so far were not examined by CT or MRI scan. Dysgenesis of the corpus callosum and ventricular dilatation seen on the MRI of this patient may be a part of this syndrome and further studies by MRI or CT scanning are needed to support this suggestion.

Dysgenesis of the corpus callosum and microphthalmia are among the main features of Aicardi syndrome of which other findings are seizures, specific chorioretinal lacunar changes, and motor and mental retardation. Its inheritance is $\mathrm{X}$ linked dominant. All cases with Aicardi syndrome are female apart from a male with $47, \mathrm{XXY}$, which is, of course, consistent with $\mathrm{X}$ linked inheritance. ${ }^{12}$

Microphthalmia is also seen in Goltz syndrome in which the characteristic features are dental abnormalities, syndactyly of the fingers/ toes, and skin abnormalities such as angiofibromatous changes around the lips and anus and atrophy and altered pigmentation in localised areas. ${ }^{13}$

Our case was diagnosed as having Lenz microphthalmia syndrome because his findings, including craniofacial abnormalities, narrow shoulders, hypoplastic clavicles, cryptorchidism, and skeletal changes in the hands and feet, are the typical characteristics of Lenz microphthalmia syndrome (table 2).

Although Goltz syndrome, Aicardi syndrome, and Lenz microphthalmia syndrome have been defined as separate entities, they have a remarkable number of common features, such as microphthalmia, skeletal
Table 2 Major abnormalities seen in Lenz micropthalmia syndrome $e^{2}$ and the findings in our patient

\begin{tabular}{|c|c|c|}
\hline & $\%$ & Our patient \\
\hline Microphthalmia & 100 & + \\
\hline Retardation & 92 & + \\
\hline Ear abnormalities & 83 & + \\
\hline Microcephaly & 83 & + \\
\hline Blepharoptosis & 75 & - \\
\hline Skeletal abnormalities & 67 & + \\
\hline Dental anomalies & 67 & + \\
\hline Digital anomalies & 58 & + \\
\hline Urogenital anomalies & 50 & + \\
\hline Cleft lip/palate & 33 & + (high arched palate) \\
\hline
\end{tabular}

changes, motor and mental retardation, and $\mathrm{X}$ linked inheritance. However, there have been some linkage studies concerned with the gene locations on the $\mathrm{X}$ chromosome (especially the $\mathrm{Xp} 22$ region) of these disorders. No gene has definitely been mapped for any of them. Friedman et $a l^{14}$ described a girl with Goltz syndrome who had a terminal deletion of the short arm of the $\mathrm{X}$ chromosome with a breakpoint in Xp22.31. Nielsen et al ${ }^{15}$ studied the $\mathrm{Xp} 22$ region in Aicardi patients by using polymorphic DNA markers. They found no evidence for a microdeletion. Graham et $a l^{16}$ excluded a location on Xp for the Lenz microphthalmia gene in a family by linkage analysis. Further molecular studies are needed to understand the genetic relationship between these syndromes.

1 Lenz W. Recessivegchlechsgebundane Microphthalmia mit multiplen Misbuldingen. $Z$ Kinderheilkd 1955;77:384

2 Trabulsi El, Lenz W, Gonzales-Ramos M, Siegel J, Macrae WG, Maumene IH. The Lenz microphthalmia syndrome. Am $¥$ Ophthalmol 1988;105:40-5.

3 Glanz A Forse A Polemeno RC Cole DEC Lenz microphthalmia. A malformation syndrome with variable microphthalmia. A malso congenital anomalies. Can 7 Ophthalmol 1983;18:41-4.

4 Kenneth L. Smith's recognizable patterns of human malformation. 4th ed. Philadelphia: Saunders, 1988:358-9.

5 Pena SDJ, Shokeir MHK. Autosomal recessive cerebrooculo-skeletal (COFS) syndrome. Clin Genet 1974;5:285

Winter RM, Baraitser M. Microphthalmia, multiple congenital anomalies. A diagnostic conundrum. London: Chapman and Hall, 1992:1092-3.

7 McKusick VA, Microphthalmia and anophthalmos with associated anomalies (MAA: Lenz dysplasia). In: Mendelian inheritance in man. Catologs of autosomal dominant, autosomal recessive and $X$-linked phenotypes. 10 th ed. Baltimore: The John Hopkins University Press, 1992:1911.

8 Jinkins JR, Whittemore AR, Bradley WG. MRI imaging of callosal and corticocallosal dysgenesis. AfNR 1989;10: callosal

9 Jeret JS, Serur D, Wisniewski KE, Lubin RA. Clinicopathalogical findings associated with agenesis of the corpus callogical findings associated with agenesis of the corpus callosum. Brain Dev 1987;9:255-64. (Erratum, Brain Dev 1989;9:567.)

10 Heyer $E$, Tremblay $M$. Variability of genetic contribution of Quebec population founders associated with some deleterious genes. Am f Hum Genet 1995;56:970-8.

11 Nijokiktijen C, de Sonneville L, Vael J. Callosal size in children with learning disabilities. Behav Brain Res 1994;64: 213-14

12 Hopkins IJ, Humphrey I, Keith GG, Susman M, Webb GC, Turner EK. The Aicardi syndrome in a $47 \mathrm{XXY}$ male. Aust Paediatr F 1979;15:278-80.

13 Goltz RW, Peterson WC, Gorlin RJ, Ravits HG. Focal dermal hypoplasia. ARC Dermatol 1962;86:708.

14 Friedman PA, Rao KW, Teplin SW, Aylsworth AS Provisional deletion mapping of the focal dermal hypoplasia (FDH) gene to Xp22.31. Am f Hum Genet 1988;43: A50.

15 Nielsen KB, Anvert M, Flodmark O, Furuskog F, BohmanValis K. Aicardi syndrome: early neurological manifestations and results of DNA studies in one patient. Am $\mathcal{F} M$ C tions and results of

16 Graham CA, McCleary BG, Malcolm S, et al. Linkage analysis in a family with $\mathrm{X}$ linked anophthalmos. $\mathcal{f}$ Med analysis in a family 